\title{
Chemical Classification and Labelling System in Malaysia: Before and After GHS
}

\author{
Azreen Shazwani Omar, Goh Choo Ta, Mohd Norhisyam Omar, Noor Hafizie Sulkafle and
} Mohd Hafizullah Harun*

In Malaysia, the Occupational Safety and Health (Classification, Packaging and Labelling of Hazardous Chemicals) Regulations 1997 (CPL Regulations) were replaced by the Occupational Safety and Health (Classification, Labelling and Safety Data Sheet of Hazardous Chemicals) Regulations 2013 (CLASS Regulations) as a step towards the implementation of the Globally Harmonized System of Chemical Classification and Hazard Communication (GHS). This paper highlights 10 significant differences between the two regulations in these aspects: (i) the legal status of reference documents; (ii) clarity of chemical classification; (iii) incorporation of environmental hazards; (iv) classification criteria; (v) their labelling presentation; (vi) use of danger symbols and hazard pictograms; (vii) sizes of danger symbols and hazard pictograms; (viii) hazard descriptions; (ix) safety data sheet; and (x) inventory submission. Although both CPL Regulations and CLASS Regulations have similar frameworks, the legal requirements outlined in both regulations differ significantly particularly in chemical classification, labelling and safety data sheet requirements, and inventory submission. The most important step forward is that the CLASS Regulations' requirement for chemicals to be classified with proper documented evidence and comprehensive hazard communication makes the chemical suppliers take greater responsibility for the chemicals they supply.

\section{Introduction}

Legal provisions related to chemical safety in Malaysian workplaces came into being only after the enactment of the Factories and Machinery Act 1967 (FMA 1967) enforced by the Department of Occupational Safety and Health (DOSH), Ministry of Human Resources, Malaysia. The FMA 1967, while mainly focusing on factory operations and machinery ${ }^{1}$ did, in general, outline the need for eliminating risks of bodily injury due to exposure to explosive, flammable,

DOI: $10.21552 / \mathrm{icrl} / 2019 / 1 / 4$

* Azreen Shazwani Omar, Institute for Environment and Development (LESTARI), Universiti Kebangsaan Malaysia (UKM) \& Department of Occupational Safety and Health (DOSH), Ministry of Human Resources (MOHR), Malaysia. Goh Choo Ta, Institute for Environment and Development (LESTARI), Universiti Kebangsaan Malaysia (UKM). Mohd Norhisyam Omar, Institute for Environment and Development (LESTARI), Universiti Kebangsaan Malaysia (UKM) \& Department of Occupational Safety and Health (DOSH), Ministry of Human Resources (MOHR), Malaysia. Noor Hafizie Sulkafle, Institute for Environment and Development (LESTARI), Universiti Kebangsaan Malaysia (UKM) \& Department of Occupational Safety and Health (DOSH), Min- poisonous or corrosive substances, and the need for equipping workers with personal protective equipment when exposed to such substances, or when in any other work-related dangerous situations. ${ }^{2}$ The provisions of FMA 1967 brought into focus the perspective that working or dealing with chemicals can be dangerous, thus chemicals need to be managed properly to avoid undesirable circumstances.

Over the years, a few other regulations under the FMA 1967 were gazetted to address specific chemical safety issues that were common during that par- istry of Human Resources (MOHR), Malaysia. Mohd Hafizullah Harun, Department of Public Health, Universiti Kebangsaan Malaysia (UKM) \& Department of Occupational Safety and Health (DOSH), Ministry of Human Resources (MOHR), Malaysia. The authors would like to acknowledge partial support from the research grants XX-2016-003 and GUP-2015-029. For correspondence: <gohchoota@ukm.edu.my>

1 R Arahman and M Z Malek, 'Safety of Machinery and Special Scheme of Inspection's Requirement towards Industry Competitiveness in Malaysia' (2016) 10 Modern Applied Science 11, 211-216.

2 Malaysia, Factories and Machinery Act 1967. 
ticular industrial era, including the Factories and Machinery (Lead) Regulations 1984, Factories and Machinery (Asbestos) Regulations 1986 and Factories and Machinery (Mineral Dust) Regulations 1989. The contents of the FMA 1967 and the regulations under it were claimed to be prescriptive in nature and were based on detailed technical provisions. ${ }^{3}$ Industries were compelled to comply with any methods, techniques, procedures, etc. outlined in FMA 1967 regardless of the presence of any other better measures prescribed for performing an activity.

The FMA 1967 was the main legislative instrument addressing occupational safety and health, as well as chemical safety, that was applicable in workplaces up until 1994, when a new act, the Occupational Safety and Health Act 1994 (OSHA 1994) was enacted. The introduction of OSHA 1994 was deemed to fit well with the country's rapid industrial development, shifting from a commodity-based economy, and resulting in an increase not only in industry size, but also in chemical use and production as well as in the number of workers involved. ${ }^{4}$ The swift development of chemicals and technologies involved resulted in increased risk of new forms of workplace hazards that could no longer be managed using the existing prescriptive legislations. ${ }^{5}$ The self-regulating nature of OSHA 1994 put the responsibility of ensuring safety and health of the workers, including those involved in chemical management at work, on the person or persons who created the risk, and those who worked with it, namely the employer and the employees. ${ }^{6}$

OSHA 1994 further outlined the safety and health of the workers and refined and established the requirement for chemical safety at the workplace with the enactment of these regulations:

1. Occupational Safety and Health (Control of Industrial Major Accident Hazards) Regulations 1996;

2. Occupational Safety and Health (Classification, Packaging and Labelling of Hazardous Chemicals) Regulations 1997;

3. Occupational Safety and Health (Prohibition of Use of Substance) Order 1999; and

4. Occupational Safety and Health (Use and Standard of Exposure to Chemicals Hazardous to Health) Regulations 2000.

As is the practice in the occupational safety and health community, drawing up the framework of any risk assessment starts with the identification of hazards. One of the aspects of hazard identification in any chemical risk assessment would be the chemical's classification which describes the intrinsic hazards of the chemical. Hence, the Occupational Safety and Health (Classification, Packaging and Labelling of Hazardous Chemicals) Regulations 1997 (CPL Regulations) were gazetted for the purpose of chemical classification and hazard communication. ${ }^{7}$ Compliance with the CPL Regulations was facilitated through three published reference documents, namely Guidelines for the Classification of Hazardous Chemicals, Guidelines for Labelling of Hazardous Chemicals, and Guidelines for the Formulation of a Chemical Safety Data Sheet (CSDS). These reference documents provide the method for classification of chemicals based on the criteria given and preparation of labels, as well as CSDS according to the format required.

Chemical classification and hazard communication is an important aspect of chemical management, but they differ from one country to another. ${ }^{8}$ More often than not, a chemical classified as toxic in one country might be classified as harmful in another, or possibly non-toxic in yet another. ${ }^{9}$ This would result in confusing hazard communication, possibly even affecting risk assessment and control of the same

3 H Singh, 'Decades of Occupational Safety and Health in Malaysia' (2004) National Institute of Occupational Safety and Health.

4 M B Mokhtar et al, 'An Essential Step for Environmental Protection: Towards a Sound Chemical Management System in Malaysia' (2010) 17 Journal of Chemical Health and Safety 2010 5, 13-20.

$5 \cup$ K Farouk et al, 'Occupational Safety and Health Committees: How Fares the Pulse of the Self-Regulatory System in Malaysian Manufacturing Firms?' (2011) 2 International Journal of Trade, Economics and Finance 5, 412-418.

6 C M Abu Bakar, 'Perspective of occupational safety and health legislation in Malaysia' in K G Rampal and I Noorhassim (eds), Occupational Safety and Health in Malaysia (National Institute of Occupational Safety and Health, 1996) 1-13.

7 Malaysia, Occupational Safety and Health (Classification, Packaging and Labelling of Hazardous Chemicals) Regulations 1997.

8 J C Silk, 'Development of a Globally Harmonized System for Hazard Communication' (2003) 206 International Journal of Hygiene and Environmental Health 4 - 5, 447-452.

9 EU Commission, 'Analysis of the Potential Effects of the Proposed GHS Regulation on Its EU Downstream Legislation' 2006; L Seguin, 'Optimizing Your Company's GHS Deployment' (2009) 16 Journal of Chemical Health and Safety 4, 5-9; G C Ta et al, 'A Comparison of Mandatory and Voluntary Approaches to the Implementation of Globally Harmonized System of Classification and Labelling of Chemicals (GHS) in the Management of Hazardous Chemicals' (2011) Industrial Health 49, 765-773. 
chemical. Therefore, in addressing this problem and fulfilling the concept of sustainable development, an internationally concerted, harmonized system for chemical classification and hazard communication, known as the Globally Harmonized System of Classification and Labelling of Chemicals (GHS) was developed..$^{10}$ The GHS document, also known as the 'purple book', is currently being adopted and adapted by countries all over the world, including Malaysia.

In Malaysia, DOSH, supporting the intention of the Ministry of International Trade and Industry (MITI) to implement GHS in Malaysia, had been reviewing the CPL Regulations since 2008 and decided to draft a new set of regulations incorporating and adopting the elements of GHS into the legal framework of OSHA 1994. Other countries such as Japan and Korea were also incorporating GHS into their respective legal frameworks. ${ }^{11}$ Five years later, the Occupational Safety and Health (Classification, Labelling and Safety Data Sheet of Hazardous Chemicals) Regulations 2013 (CLASS Regulations) were gazetted on $11^{\text {th }}$ October 2013, thus revoking the CPL Regulations in Malaysia. ${ }^{12}$ As the drafting of the CLASS Regulations started in 2008, DOSH decided to adopt the $3^{\text {rd }}$ revised edition of GHS (the most current edition of the purple book at the time), turning it into a customized and legally binding document,

10 C Winder et al, 'The Development of the Globally Harmonized System (GHS) of Classification and Labelling of Hazardous Chemicals' (2005) 125 Journal of Hazardous Materials 1, 29-44; K Koshy et al, 'Implementing the Hazard Communication Standard Final Rule: Lessons learned' (2015) 22 Journal of Chemical Health and Safety 2, 23-31.

11 I J Yu et al, 'Korean Initiatives of GHS Activities' (2005) 43 Industrial Health, 709-711; $\mathrm{H}$ Jonai, 'Implementation of the GHS in Japan' (2008) 46 Industrial Health, 443-7.

12 Malaysia, Occupational Safety and Health (Classification, Labelling and Safety Data Sheet of Hazardous Chemicals) Regulations 2013.

13 Malaysia, 'Industry Code of Practice on the Chemical Classification and Hazard Communication 2014' Department of Occupational Safety and Health, Malaysia.

14 Department of Occupational Safety and Health, CLASS Regulations. <http://www.dosh.gov.my/index.php/en/chemical -management/class-regulations> accessed on 30 March 2018.

15 Malaysia, Guidelines for the Classification of Hazardous Chemicals, Department of Occupational Safety and Health, 1997; Malaysia, Guidelines for Labelling of Hazardous Chemicals, Department of Occupational Safety and Health, 1997; Malaysia, Guidelines for the Formulation of a Chemical Safety Data Sheet, Department of Occupational Safety and Health, 1997.

16 Malaysia, 'Industry Code of Practice on the Chemical Classification and Hazard Communication 2014', Department of Occupational Safety and Health, Malaysia. ie Industry Code of Practice of Chemical Classification and Hazard Communication (ICOP CHC), to support the implementation of the CLASS Regulations. ${ }^{13}$ The ICOP CHC was gazetted on $16^{\text {th }}$ April 2014 and it is a legally binding document. ${ }^{14}$

As the CPL Regulations had been revoked and replaced by CLASS Regulations, chemical suppliers had to make appropriate arrangements to conform to the new set of regulations. Both the CPL Regulations and CLASS Regulations were drafted with the same intentions, to provide legal provisions to ensure that the chemicals supplied or used in any place of work would be classified accordingly, and with proper hazard communication to ensure the safety and health of the workers involved in the handling of the chemicals. However, there are some significant differences that should be highlighted to the Malaysian industries to ensure better understanding and compliance. Hence this paper aims delineate the differences between the CPL Regulations and CLASS Regulations.

\section{Materials and Methods}

The CPL Regulations (including three reference documents) and CLASS Regulations (including ICOP $\mathrm{CHC}$ ) were used as the materials for comparison purposes. The analysis used the CLASS Regulations as the main reference, and then focused on chemical classification, labelling, packaging, safety data sheet and inventory of hazardous chemicals.

\section{Results and Discussion}

\section{Legal Status of Reference Documents}

Compliance with the CPL Regulations and CLASS Regulations is based on the requirements stipulated in the respective sets of regulations. The technical requirements are provided in different reference documents: three reference documents (ie on classification, labelling and SDS $)^{15}$ under CPL Regulations but only one reference document known as ICOP $\mathrm{CHC}^{16}$ under CLASS Regulations.

The CPL Regulations as well as the three reference documents are based on EU Directive 67/548/EEC and 1999/45/EC. Although all three reference documents describe the technical requirements under the 
CPL Regulations, they are not legally binding. The reference document under CLASS Regulations, ICOP $\mathrm{CHC}$, however, is a legally binding document. The ICOP CHC is well-defined under the CLASS Regulations, hence if a chemical supplier does not follow the technical requirements stated in ICOP CHC, he is deemed to be non-compliant with CLASS Regulations. The introduction of ICOP CHC has ensured consistency for the criteria of chemical classification and hazard communication among chemical suppliers.

\section{Clarity of Chemical Classification}

The most obvious difference that can be observed immediately between the two Regulations is in the number of hazard classifications of chemicals. In the CPL Regulations, the hazard classes are as listed in Table 1. Chemicals are classified into five hazard classes based on physicochemical properties and/or health effects, which are divided further into the specific hazard classes.

Although the hazard classification in CPL Regulations looks straightforward, it is actually based on consolidation of hazardous properties. For example, chemicals classified as toxic includes all chemicals with acute toxicity, specific target organ toxicity from single or repeated exposure, carcinogenicity, mutagenicity and/or teratogenic effects. These properties are represented by the risk phrases listed in Schedule III of the CPL Regulations. Risk phrases are significant indications of the hazards posed by the chemical. The challenge in the CPL Regulations is that the correlation between the risk phrase and hazard class is not distinct, and is not indicated clearly in the main legal text, although such correlations are indicated in the non-legally binding reference documents.

Another important aspect to note in the CPL Regulations is that the hazard classes are ordered in a hierarchy, known as the degree of hazard, in which the hazardous chemical will only be represented in the highest degree of hazard in each classification based on physicochemical properties and health effects. The hierarchy of the degree of hazard is depicted in Table 2 with the topmost hazard class representing the highest degree of hazard.

The degree of hazard provision significantly affects the hazard communication component of the
CPL Regulations. As a result, only the danger symbol which represents the highest degree of hazard for each physical and/or health hazard will be included in the label. For example, if a chemical is classified as very toxic and corrosive, by assigning to it a degree of hazard, only the danger symbol for very toxic will be shown on the label. This has, to a certain extent, implicated the label presentation of hazardous chemicals during the CPL Regulations' enforcement.

In CLASS Regulations, the hazard classification is based on the CPL Regulations framework but it is further refined and specified according to the different physical properties and health effects. The classifications are made to represent and describe the hazards directly. The hazard classification for CLASS Regulations, as listed in Table 3, consists of hazard classes and hazard categories. Each hazard category is defined based on the criteria of classification detailed in the legally binding document known as ICOP CHC, and is also in line with GHS $3^{\text {rd }}$ revised edition. Nonetheless, due to the building block approach, the CLASS Regulations do not adopt Category 4 (flammable liquids), Category 5 (acute toxicity oral, dermal and inhalation), Category 3 (skin corrosion or irritation), Category 2 (aspiration hazard), and Category 2 and 3 (hazardous to aquatic environment - acute hazard).

It can be seen that one hazard class in CPL Regulations might represent a few hazard classifications so chemical suppliers need to ascertain the correlation between the hazard classes and the risk phrases. On the other hand, the hazard classes for CLASS Regulations are more descriptive in nature and depict the actual represented hazard. The entire hazard of a particular chemical can be known by just going through the classification of the chemical without having to refer to any additional phrases or statements.

\section{Incorporation of Environmental Hazards}

Another major noticeable difference between CPL Regulations and CLASS Regulations is the requirement for environmental hazards classification to be spelt out in CLASS Regulations, which is not included in CPL Regulations. The rationale for incorporating environmental hazards in CLASS Regulations is to facilitate GHS implementation in Malaysia, result- 
ing in a single instrument that incorporates physical, health and environmental hazards as required by GHS.

The environmental hazards classification outlined in the CLASS Regulations adopts the same concept of classification as the physical and health hazards discussed earlier. The environmental hazards classification in the CLASS Regulations is presented in Table 3. An example of the criteria that will result in the classification of a chemical as hazardous to the aquatic environment - acute toxicity, is in Table 4. Although the environmental hazards classification have been newly introduced into the CLASS Regulations, the hazard statements used to describe the hazard are similar to the risk phrases listed in CPL Regulations (Schedule III). However, no classification criteria are mentioned in the CPL Regulations.

\section{Classification Criteria}

The classification criteria for CPL Regulations are provided in Schedule I of the regulations and are detailed comprehensively in the Guidelines for the Classification of Hazardous Chemicals. All of the classification criteria for CLASS Regulations, however, are provided in the ICOP CHC. For the purpose of illustration in this paper, one physicochemical property/physical hazard and one health effect/health hazard are selected for comparison.

For the comparison of physical hazards, the classification criteria for flammable liquid in both CPL Regulations and CLASS Regulations are compared in parallel in Table 5. It is noticed that the flash points are different in these two regulations and this will lead to different chemical classification results for the same chemical. For example, a chemical with flash point $58^{\circ} \mathrm{C}$ is not classified as flammable (liquid) under the CPL Regulations but it is now classified as flammable liquid category 3.

The comparison of health hazards between the CPL regulations and CLASS is shown in Table 6. It is noticed that the cut-off values for the acute toxicity (oral, dermal and inhalation) between CPL regulations and CLASS regulations are different. For example, the classification criteria in CLASS Regulations for acute toxicity (oral) goes up to an $\mathrm{LD}_{50}$ of $2000 \mathrm{mg} / \mathrm{kg}$, a much larger range, compared to 500 $\mathrm{mg} / \mathrm{kg}$ in CPL Regulations (Table 6) with a different range of values for each category. This implies that chemical suppliers cannot convert the health hazards directly from CPL Regulations to CLASS Regulations, instead, they have to ascertain the $\mathrm{LC}_{50}$ values for the chemicals first before they reclassify the chemicals under CLASS regulations.

In CPL Regulations, the criteria for acute toxicity via inhalation only consider values of $\mathrm{LC}_{50}$ for vapours, whereas the criteria in CLASS Regulations for vapours also include values of $\mathrm{LC}_{50}$ for gases and mist/dust as well. Moreover, the classification of toxicity in CPL Regulations that includes properties of carcinogenic, mutagenic and teratogenic effects is now being assigned as different hazard classes in CLASS Regulations. Hence, these significant changes in hazard classes and classification criteria should be noted by the chemical suppliers, and taken into consideration when shifting their compliance from CPL Regulations to CLASS Regulations. On top of that, all of the classifications made under CPL Regulations are not required to be documented. Under the CLASS Regulations, however, DOSH requires chemical suppliers to keep a record of classification to justify the classifications of their chemicals (for both substances and mixtures), made according to the classification system required by the regulations.

\section{Labelling Presentation}

Another important difference in the implementation of both of the regulations is the hazard communication aspect. Both regulations have specific provisions on hazard communication in terms of providing proper labels and safety data sheets. Table 7 compares labelling requirements for both regulations. The five elements compared serve the same purpose, regardless of differences in the terms used. Hazard statements are statements that describe the nature of hazards, replacing the risk phrases used previously. Precautionary statements are phrases used to describe recommended measures to mitigate or prevent adverse effects from exposure to hazardous chemicals, replacing the safety phrases used in CPL Regulations. In addition to the five elements, there is another element in the current regulations which is the signal word, 'Danger' or 'Warning', which acts as an indication of the severity of the hazard. 


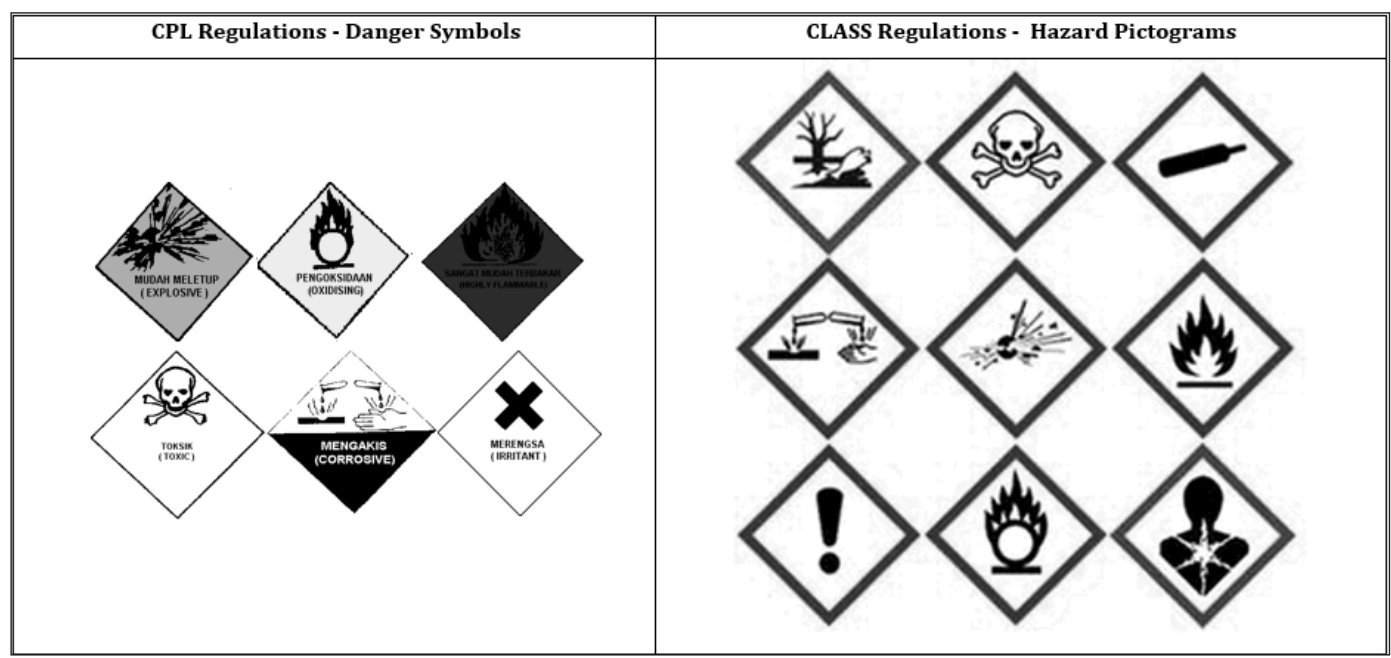

Figure 1: Comparison between Danger Symbols and Hazard Pictograms used

Due to the changes in this aspect of the chemical classification, the requirements of labelling of hazardous chemicals have also been altered. The previous CPL Regulations required hazardous chemicals to be classified in the highest degree of hazard in each category; in contrast, CLASS Regulations require all of the hazards of a chemical to be considered. Therefore, despite having similar requirements for the labelling elements of hazardous chemicals, the presentation of information on the label differs greatly.

\section{Danger Symbols and Hazard Pictograms}

The use of symbols to depict hazards visually is apparent in both regulations. One of the crucial changes made to the labelling elements is the change of danger symbols (in CPL Regulations) to hazard pictograms (in CLASS Regulations). Figure 1 compares the danger symbols and hazard pictograms used in the different regulations.

The danger symbols in CPL Regulations, other than using colours to differentiate between the symbols, are quite self-explanatory compared to the pictograms used in CLASS Regulations. This is because the danger symbols incorporate indication of danger (in words) while the hazard pictograms only consist of symbols with no use of colours allowed except for the red borders. Nonetheless, the use of the word for danger, to a certain extent, has negated the purpose of using diagrams to convey hazard information.

\section{Sizes of Danger Symbols and Hazard Pictograms}

Another requirement pertaining to danger symbols and hazard pictograms that was compared was the size requirements outlined in the respective regulations. CPL Regulations require a danger symbol to be one tenth of the area of the label containing all other labelling elements outlined in the CPL Regulations. It is also important to note that CPL Regulations require that chemicals be classified in the highest degree of hazard for each classification based on physicochemical properties and health effects. This would result in the labels for hazardous chemicals under CPL Regulations having a maximum of only two danger symbols per label (one for a physicochemical property and one for a health hazard), enabling chemical suppliers to predetermine the size of the label required.

However, the shift to CLASS Regulations does not only affect the number and appearance of the particular labelling elements but also the sizes of the pictograms. Requiring all hazard classifications to be conveyed on the label would reduce the size of each pictogram to one-fifteenth of the label area containing all other elements. If the area of one-fifteenth of the label calculated (equivalent to the area of one pic- 
togram) turns out to be less than $100 \mathrm{~mm}^{2}$, then the area of the pictogram would assume the minimum required area of $100 \mathrm{~mm}^{2}$. Chemical suppliers with chemicals that are classified as hazardous in a few hazard classes would need to fit in all the related pictograms on the label, making label size determination a dynamic process, depending on the hazard classification of the chemicals.

\section{Hazard Description}

Although not explicitly spelt out in the CPL Regulations, the accompanying labelling guidelines state that only a maximum of four risk phrases, representing the highest degree of hazards, should appear on the label. Subsequently, only a maximum of four safety phrases, corresponding to the risk phrases involved, should appear on the label as well.

Succeeding the CPL Regulations, the CLASS Regulations no longer require classification of chemicals based on the highest degree of hazard. Thus, the label should include information on all of the hazards of a hazardous chemical. There is no limit to the number of hazard statements that can be included in the label because all corresponding hazards must be represented. However, the limit for the maximum number of precautionary statements is just six that are the most stringent among all relevant precautionary statements. Additional precautionary statements may be included if deemed necessary.

As a result, taking into consideration the requirements mentioned for pictograms as well as hazard and precautionary statements, no specific format for the placement of the labelling elements has been determined for CLASS Regulations as there is an infinite number of classification possibilities as compared to CPL Regulations that only need one highest degree of hazard each for physicochemical properties and health effects.

\section{SDS}

Another hazard communication element that has been affected due to the revocation of CPL Regulations is the Chemical Safety Data Sheet (CSDS), currently known as the Safety Data Sheet (SDS). Currently, CLASS Regulations explicitly dictate that the SDS shall contain 16 sections, and that the sections are to be in the order specified in the regulations. The sections are compared in parallel in Table $\mathbf{8}$.

The sections laid out in both regulations do not differ much in terms of headings of the sections. There is an addition of one section; Section 15: Regulatory information, which was not previously required. The order of sections 2 and 3 are also switched, indicating that the information on hazard identification has a higher priority compared to the information on composition of ingredients. The current SDS is not only required to have 16 sections, laid out in the specific order, the CLASS Regulation also enforces the 'minimum information' needed in SDS. Examples of the minimum information required for the first 3 sections are listed in Table 9. CPL Regulations do not specify that the sections in CSDS are to be according to the order mentioned in the legal text and no minimum information requirement is made in the regulations. However, the guidelines for the formulation of a chemical data sheet detail the information needed in each section of the CSDS.

Although the superficial differences between the SDS requirements of the two regulations are somewhat apparent, formulation of the SDS in accordance with the CLASS Regulations is more than just rearranging the information into the respective headings. SDS compliance with CLASS Regulations requires the chemical supplier to go through the essential steps of classifying the chemicals according to the criteria specified in order to obtain the correct information needed in each section. For example, proper chemical classification will ensure that information in Section 2: Hazard information of the SDS, is reliable and justifiable. This will then be correlated and supported with the information presented in Section 9: Physical, chemical properties; Section 11: Toxicological information; and Section 12: Ecological information, among others. Thus, conversion of CSDS to SDS would not be just a matter of rearrangement of information but would definitely require extensive information compilation and analysis to ensure compliance with the requirements of SDS under CLASS Regulations.

\section{Inventory Submission}

Lastly, the CLASS Regulations have introduced a new requirement for hazardous chemical inventory submission by chemical suppliers. The chemical suppli- 


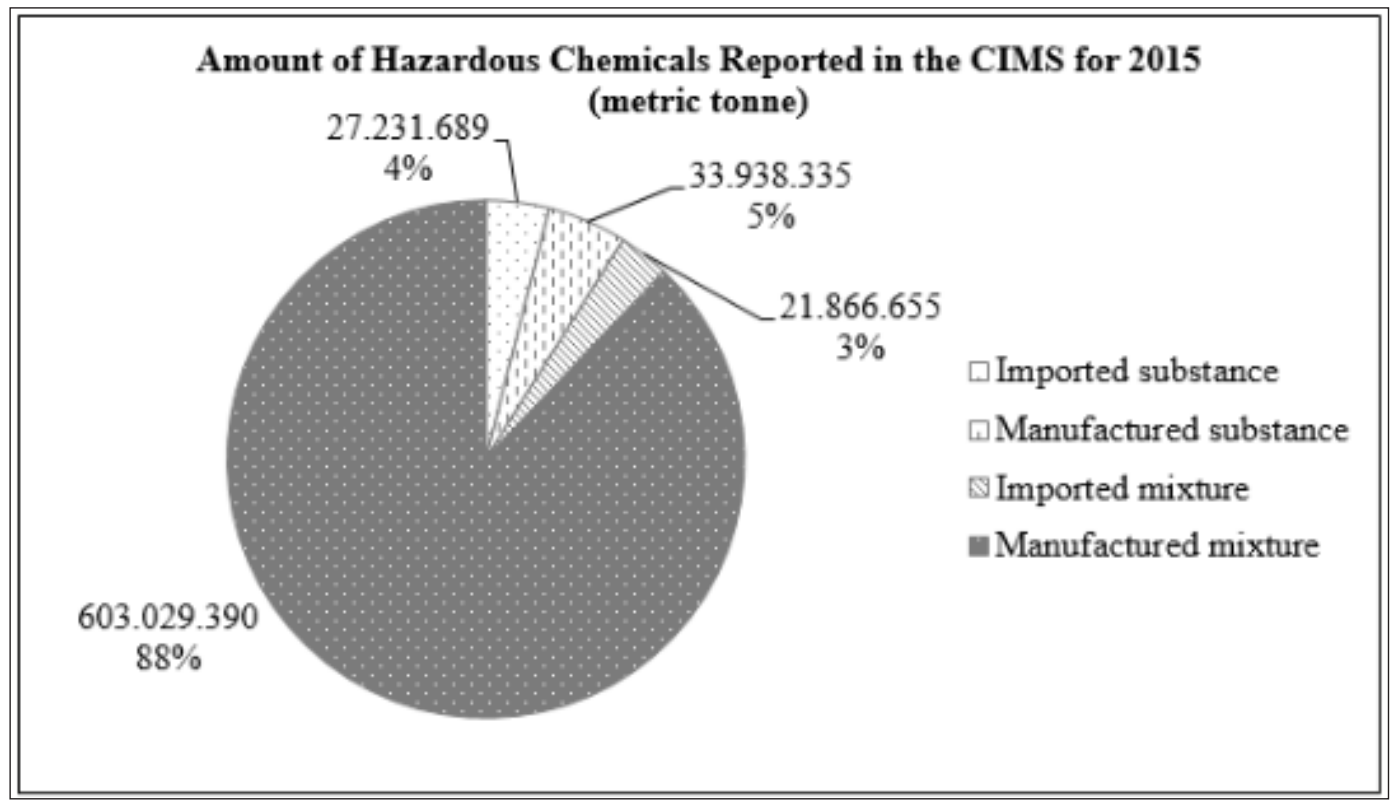

Figure 2: Amount of Hazardous Chemicals Reported in CIMS for 2015

ers are required to submit an annual inventory of imported and manufactured hazardous chemicals of a quantity of one metric tonne and above per year. The inventory should include such information as listed: (i) the product identifier; (ii) the name of the hazardous chemicals; (iii) the composition and ingredients of a hazardous chemical; (iv) the hazard classification; and (v) the total quantity of each hazardous chemical imported or supplied.

The method of inventory submission in the CLASS Regulations is not specified; however, an online system known as the Chemical Information Management System (CIMS) has been developed for the purpose of facilitating inventory submission by the importers and/or manufacturers. CIMS can be easily accessed online. Submission of inventories officially started in 2016 for submission of 2015 data. The statistics on the amount of hazardous chemicals, substances and mixtures imported and manufactured in 2015 obtained from the system are presented in Figure 2. Approximately 700 million tonnes of hazardous chemicals were imported and manufactured in Malaysia in 2015 irrespective of industrial sector. The greatest amount was contributed by manufactured mixtures which totalled 600 million metric tonnes for that year. This is due to the manufacturing of petroleum products currently dominating Malaysian commodities. Currently there are 766 chemical suppliers registered with the CIMS. ${ }^{17}$

\section{Conclusion}

The revocation of CPL Regulations by the CLASS Regulations has come at an opportune time to revolutionize chemical management in the Malaysian workplace. The comparison between the two sets of regulations highlighted in this paper could serve as a reference for chemical suppliers and to enable a better understanding of the requirements of the current regulations. The refinement of the legal requirements and the adoption of an international system of chemical classification in the CLASS Regulations could definitely improve the chemical classification and hazard communication system as well as overall chemical management in Malaysia.

17 Department of Occupational Safety and Health, Chemical Information Management System <http://cims.dosh.gov.my> accessed on 30 March 2018. 


\section{Appendix: Tables 1 - 9}

Hazard Classification in CPL Regulations(Table 1)

\begin{tabular}{|l|l|}
\hline Classification based on: & Hazard Class \\
\hline \multirow{5}{*}{ Physicochemical properties } & Explosive \\
\cline { 2 - 2 } & Oxidizing \\
\cline { 2 - 2 } & Extremely flammable \\
\cline { 2 - 2 } & Highly flammable \\
\cline { 2 - 2 } & Flammable \\
\hline \multirow{5}{*}{ Health effect } & Very toxic \\
\cline { 2 - 2 } & Toxic \\
\cline { 2 - 2 } & Harmful \\
\cline { 2 - 2 } & Corrosive \\
\cline { 2 - 2 } & Irritant \\
\hline
\end{tabular}

\begin{tabular}{||c|c||}
\hline Physicochemical properties & Health effect \\
\hline Explosive & Very toxic \\
$\sqrt{ }$ & $\sqrt{ }$ \\
Oxidizing & Toxic \\
$\Omega$ & $\Omega$ \\
Extremely flammable & Corrosive \\
$\sqrt{ }$ & $\Omega$ \\
Highly flammable & Harmful \\
$\Omega$ & $\Omega$ \\
Flammable & Irritant \\
\hline
\end{tabular}

Hierarchy of the Degree of Hazard (Table 2) 
Hazard Classification in CLASS Regulations (Table 3)

\begin{tabular}{|c|c|c|c|c|c|c|c|c|c|}
\hline Hazard Classifica- & \multicolumn{2}{|r|}{ Hazard Class } & \multicolumn{7}{|c|}{ Hazard Category } \\
\hline \multirow{16}{*}{ Physical Hazard } & 1 & Explosives & $\begin{array}{l}\text { Unstable } \\
\text { explosive }\end{array}$ & Div 1.1 & Div 1.2 & Div 1.3 & $\begin{array}{l}\text { Div } \\
1.4\end{array}$ & $\begin{array}{l}\text { Div } \\
1.5\end{array}$ & $\begin{array}{l}\text { Div } \\
1.6\end{array}$ \\
\hline & 2 & Flammable gases & Cat 1 & Cat 2 & & & & & \\
\hline & 3 & $\begin{array}{l}\text { Flammable } \\
\text { aerosols }\end{array}$ & Cat 1 & Cat 2 & & & & & \\
\hline & 4 & $\begin{array}{l}\text { Flammable liq- } \\
\text { uids }\end{array}$ & Cat 1 & Cat 2 & Cat 3 & & & & \\
\hline & 5 & Flammable solids & Cat 1 & Cat 2 & & & & & \\
\hline & 6 & Oxidizing gases & Cat 1 & & & & & & \\
\hline & 7 & Oxidizing liquids & Cat 1 & Cat 2 & Cat 3 & & & & \\
\hline & 8 & Oxidizing solids & Cat 1 & Cat 2 & Cat 3 & & & & \\
\hline & 9 & $\begin{array}{l}\text { Gases under pres- } \\
\text { sure }\end{array}$ & $\begin{array}{l}\text { Com- } \\
\text { pressed } \\
\text { gas }\end{array}$ & $\begin{array}{l}\text { Lique- } \\
\text { fied gas }\end{array}$ & $\begin{array}{l}\text { Refrigerat- } \\
\text { ed gas }\end{array}$ & $\begin{array}{l}\text { Dis- } \\
\text { solved } \\
\text { gas }\end{array}$ & & & \\
\hline & 10 & $\begin{array}{l}\text { Self-reactive } \\
\text { chemicals }\end{array}$ & Type A & Type B & Type C & Type D & $\begin{array}{l}\text { Type } \\
\text { E }\end{array}$ & $\begin{array}{l}\text { Type } \\
\text { F }\end{array}$ & $\begin{array}{l}\text { Type } \\
\text { G }\end{array}$ \\
\hline & 11 & $\begin{array}{l}\text { Pyrophoric liq- } \\
\text { uids }\end{array}$ & Cat 1 & & & & & & \\
\hline & 12 & Pyrophoric solids & Cat 1 & & & & & & \\
\hline & 13 & $\begin{array}{l}\text { Self-heating } \\
\text { chemicals }\end{array}$ & Cat 1 & Cat 2 & & & & & \\
\hline & 14 & $\begin{array}{l}\text { Chemicals which, } \\
\text { in contact with } \\
\text { water, emit flam- } \\
\text { mable gases }\end{array}$ & Cat 1 & Cat 2 & Cat 3 & & & & \\
\hline & 15 & Organic peroxides & Type A & Type B & Type C & Type D & $\begin{array}{c}\text { Type } \\
\text { E }\end{array}$ & $\begin{array}{l}\text { Type } \\
\text { F }\end{array}$ & $\begin{array}{c}\text { Type } \\
\text { G }\end{array}$ \\
\hline & 16 & $\begin{array}{l}\text { Corrosive to met- } \\
\text { als }\end{array}$ & Cat 1 & & & & & & \\
\hline
\end{tabular}




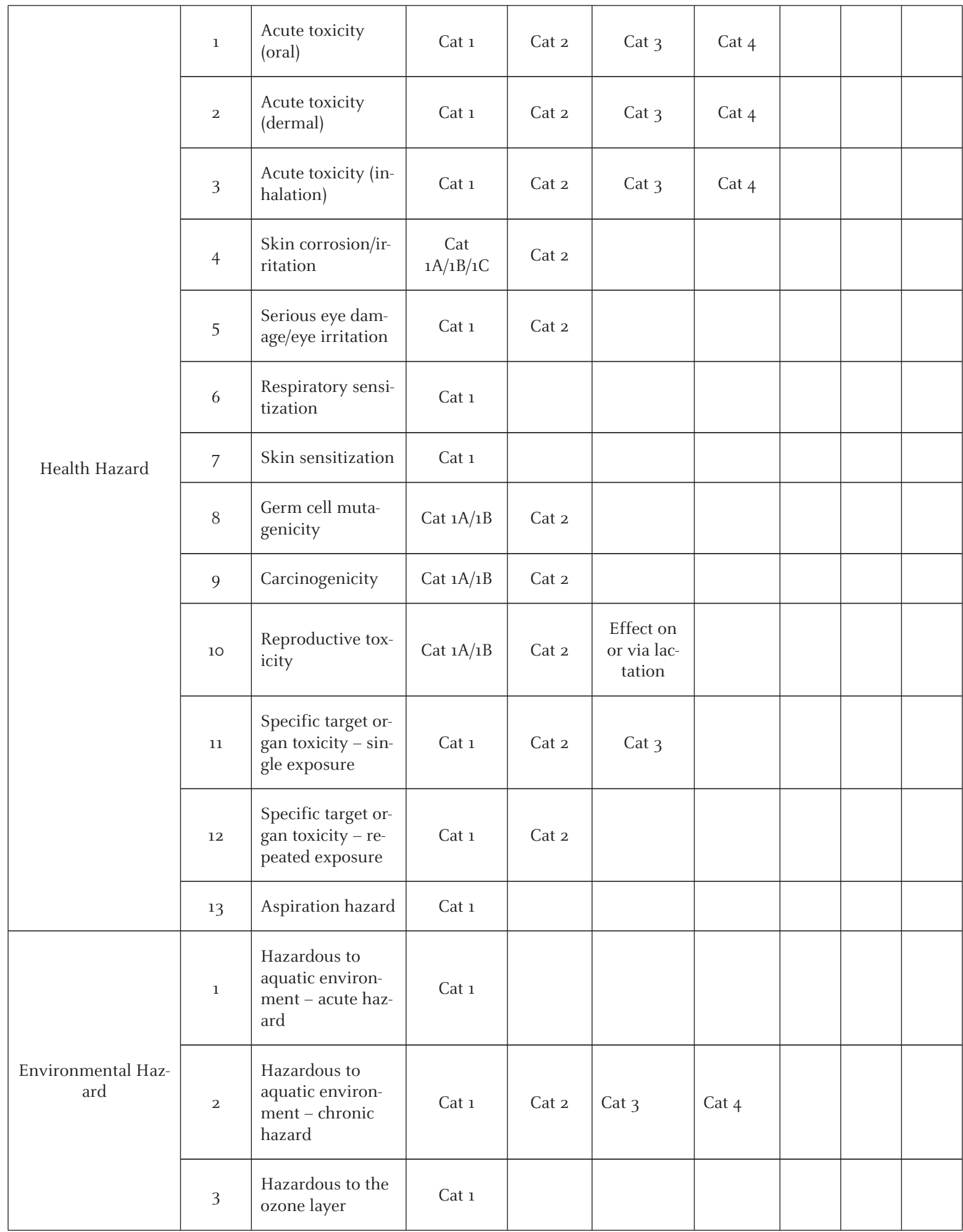




Classification Criteria for Chemicals Hazardous
to the Aquatic Environment - Acute Toxicity (Table
4)
\begin{tabular}{|l|l|}
\hline $\begin{array}{l}\text { Hazardous to the aquatic environment - } \\
\text { acute toxicity }\end{array}$ & Criteria \\
\hline $\begin{array}{l}\text { Category 1 } \\
96-h r \text { LC } 50 \text { (for fish) } \\
48 \text {-hr EC50 (for crustacean) } \\
72-\text { or } 96-h r \text { ErC50 (for algae or other aquatic } \\
\text { plants) }\end{array}$ & $\begin{array}{l}\leq 1 \mathrm{mg} / 1 \\
\text { and/or } \\
\text { and/or } / 1 \\
\leq 1 \mathrm{mg} / 1\end{array}$ \\
\hline
\end{tabular}

Comparison of Flammable Liquid Criteria Between CPL and CLASS Regulations (Table 5)

\begin{tabular}{|l|l|l|l|}
\hline \multicolumn{2}{|c|}{ CPL Regulations } & \multicolumn{2}{c|}{ CLASS Regulations } \\
\hline $\begin{array}{l}\text { Extremely flam- } \\
\text { mable (liquid) }\end{array}$ & $\begin{array}{l}\text { Flash point }<0^{\circ} \mathrm{C} \text { and a boiling point } \\
\leq 35^{\circ} \mathrm{C} .\end{array}$ & Flammable liquid category 1 & $\begin{array}{l}\text { Flash point }<23^{\circ} \mathrm{C} \text { and initial boil- } \\
\text { ing point } \leq 35^{\circ} \mathrm{C}\end{array}$ \\
\hline $\begin{array}{l}\text { Highly flamma- } \\
\text { ble (liquid) }\end{array}$ & $\begin{array}{l}\text { Flash point }<21^{\circ} \mathrm{C} \text { but which are not } \\
\text { extremely flammable. }\end{array}$ & Flammable liquid category 2 & $\begin{array}{l}\text { Flash point }<23^{\circ} \mathrm{C} \text { and initial boil- } \\
\text { ing point }>35^{\circ} \mathrm{C} .\end{array}$ \\
\hline $\begin{array}{l}\text { Flammable (liq- } \\
\text { uid) }\end{array}$ & Flash point $\geq 21^{\circ} \mathrm{C}$, and $\leq 55^{\circ} \mathrm{C}$. & Flammable liquid category 3 & Flash point $\geq 23^{\circ} \mathrm{C}$ and $\leq 60^{\circ} \mathrm{C}$. \\
\hline
\end{tabular}

\begin{tabular}{|c|c|c|c|c|}
\hline Oral (mg/kg) & $L_{50} \leq 5$ & $5<\mathrm{LD}_{50} \leq 50$ & $50<$ LD $_{50} \leq 300$ & $300<$ LD $_{50} \leq 2000$ \\
\hline CPL & \multicolumn{2}{|c|}{ Very toxic } & Harmful & \\
\hline CLASS & Cat. 1 & Cat. 2 & Cat. 3 & Cat. 4 \\
\hline Dermal (mg/kg) & LD $_{50} \leq 50$ & $50<$ LD $_{50} \leq 200$ & $200<$ LD $_{50} \leq 1000$ & $1000<$ LD $_{50} \leq 2000$ \\
\hline CPL & Very toxic & Toxic & \multicolumn{2}{|c|}{ Harmful } \\
\hline CLASS & Cat. 1 & Cat. 2 & Cat. 3 & Cat. 4 \\
\hline $\begin{array}{c}\text { Inhalation via } \\
\text { vapour (mg/L) }\end{array}$ & $\mathrm{LD}_{50} \leq 0.5$ & $0.5<\mathrm{LC}_{50} \leq 2.0$ & $2.0<\mathrm{LC}_{50} \leq 10$ & $10<\mathrm{LC}_{50} \leq 20$ \\
\hline CPL & Very toxic & Toxic & \multicolumn{2}{|c|}{ Harmful } \\
\hline CLASS & Cat. 1 & Cat. 2 & Cat. 3 & Cat. 4 \\
\hline
\end{tabular}

Comparison of Acute Toxicity (Oral, Dermal and Inhalation) between CPL and CLASS Regulations (Table 6) 
Comparison of Labelling Elements in both Regulations (Table 7)

\begin{tabular}{|c|c|c|}
\hline No & CPL Regulations labelling elements & CLASS Regulations labelling elements \\
\hline 1 & Name of hazardous chemical & Supplier identification \\
\hline 2 & Name, address and telephone number of supplier & Hazard pictogram \\
\hline 3 & Danger symbol and indication of danger & Hazard statement \\
\hline 4 & Nature of special risk (risk phrase) & Precautionary statement \\
\hline 5 & Safety precautionary measures (safety phrase) & Signal word \\
\hline 6 & & \\
\hline
\end{tabular}

\section{Comparison of CSDS and SDS Section Layout (Table 8)}

\begin{tabular}{|c|c|c|}
\hline Section & CPL Regulations & CLASS Regulations \\
\hline 1. & Product, company identification & Product and company information \\
\hline 2. & Composition information on ingredients & Hazards identification \\
\hline 3. & Hazards identification & Composition information on ingredients \\
\hline 4. & First aid measures & First aid measures \\
\hline 5 . & Fire fighting measures & Fire fighting measures \\
\hline 6. & Accidental release measures & Accidental release \\
\hline 7. & Handling and storage & Handling and storage \\
\hline 8. & Exposure controls, personal protection & Exposure controls, personal protection \\
\hline 9 . & Physical, chemical properties & Physical, chemical properties \\
\hline 10. & Stability and reactivity & Stability and reactivity \\
\hline 11. & Toxicological information & Toxicological information \\
\hline 12. & Ecological information & Ecological information \\
\hline 13. & Disposal considerations & Disposal considerations \\
\hline 14. & Transport information & Transport information \\
\hline
\end{tabular}




\begin{tabular}{|c|l|l|}
\hline 15. & $\begin{array}{l}\text { Date of preparation of the Chemical Safety Data } \\
\text { Sheet }\end{array}$ & Regulatory information \\
\hline 16. & Other information & Other information \\
\hline
\end{tabular}

Example of Minimum Information Required in each Section of the SDS (Table 9)

\begin{tabular}{|c|c|c|}
\hline Section & Title of Section & Minimum Information \\
\hline 1. & $\begin{array}{l}\text { Identification of the hazardous } \\
\text { chemical and of the supplier }\end{array}$ & $\begin{array}{l}\text { (a) Product identifier; } \\
\text { (b) Other means of identification; } \\
\text { (c) Recommended use of the chemical and restrictions on use; } \\
\text { (d) Details of principal suppliers (including name, address, phone num- } \\
\text { ber, etc.); } \\
\text { (e) Emergency phone number. }\end{array}$ \\
\hline 2. & Hazard identification & $\begin{array}{l}\text { (a) Classification of the substance/mixture and any nation or regional } \\
\text { information; } \\
\text { (b) Label elements (hazard pictogram or symbol, signal word, hazard } \\
\text { statement and precautionary statements). Hazard symbols may be } \\
\text { provided as a graphical reproduction of the symbols in black and white or } \\
\text { name of the symbols e.g. 'flame', 'skull and crossbones'; } \\
\text { (c) Other hazards which do not result in classification (e.g. dust explosion } \\
\text { hazard) or are not covered by the Regulations. }\end{array}$ \\
\hline 3. & $\begin{array}{l}\text { Composition and information of } \\
\text { the ingredients of the hazardous } \\
\text { chemical }\end{array}$ & $\begin{array}{l}\text { Substance } \\
\text { (a) Chemical identity; } \\
\text { (b) Common name, synonyms, etc; } \\
\text { (c) CAS number and other unique identifiers; } \\
\text { (d) Impurities and stabilizing additives which are themselves classified } \\
\text { and which contribute to the classification of the substance. } \\
\text { Mixture } \\
\text { The chemical identity and concentration or concentration ranges of all } \\
\text { ingredients which are hazardous and are present at or above cut-off } \\
\text { value. }\end{array}$ \\
\hline
\end{tabular}

